\title{
Local and Targeted Drug Delivery for Bone Regeneration
}

\begin{abstract}
While experimental bone regeneration approaches commonly employ cells, technological hurdles prevent translation of these therapies. Alternatively, emulating the spatiotemporal cascade of endogenous factors through controlled drug delivery may provide superior bone regenerative approaches. Surgically placed drug depots have clinical indications. Additionally, noninvasive systemic delivery can be used as needed for poorly healing bone injuries. However, a major hurdle for systemic delivery is poor bone biodistribution of drugs. Thus, peptides, aptamers, and phosphate-rich compounds with specificity towards proteins, cells, and molecules within the regenerative bone microenvironment may enable the design of targeted carriers with bone biodistribution greater than that achieved by drug alone. These carriers, combined with osteoregenerative drugs and/or stimuli-sensitive linkers, may enhance bone regeneration while minimizing off-target tissue effects.
\end{abstract}




\section{Introduction and Motivation}

Trauma, osteoporosis, and genetic disease cause approximately 6 million fractures in the United States annually [1]. Between five and ten percent of fractures result in delayed union or non-union, with age, smoking, and diabetes as common comorbidities of poor healing $[1,2]$. Successful bone regeneration requires a complex and orchestrated cascade of cells and growth factors [3-6]. To emulate this complex cascade, regenerative strategies often employ cell transplantation and/or growth factor delivery. While each of these approaches has yielded different levels of success clinically, there are still significant technological challenges.

To achieve translation of cell-based therapies, there are many hurdles to overcome. For bone regeneration, mesenchymal stem cells (MSCs) are commonly used, as they can differentiate to cells required for bone healing (osteoblasts and chondrocytes). However, other cells (e.g., inflammatory cells, endothelial cells) that play important roles in bone regeneration may also be included. A challenge to the use of any cell type is assurance of cellular uniformity. With MSCs as an example, the International Society for Cellular Therapy (ISCT) issued three criteria for identifying MSCs: plastic adherence, specific cell surface marker expression, and tri-lineage potential [7]. Additional gains in uniformity have been achieved through GMP-compliant isolation procedures [8], culture conditions [9,10], and cryopreservation techniques [11,12]. There are now Food and Drug Administration GMP-approved facilities (the NIH BMSC Transplantation Center and the Upstate New York Stem Cell cGMP Facility) that generate MSCs for clinical investigations [13]. However, cell-based therapies require significant lead-time to achieve cell quantities necessary for many regenerative approaches [14]. Further, these approaches still may fall short due to inconsistent and or unpredictable outcomes resulting from donor-to-donor and batch-to-batch variability of cells. For example, it has been shown that 
patients with many co-morbidities, such as age, osteoporosis, genetic defects, infection, obesity, diabetes, and smoking, exhibit reduced MSC potency and number resulting in poor bone regeneration [15]. While it is possible to transplant regenerative cell types, including MSCs or MSCs pre-conditioned with small molecule drugs [16] or augmented with genetic manipulations [17] to encourage osteogenesis or microenvironmental modulation [18], to date no MSC-based regenerative strategy is approved for clinical use [19].

Nevertheless, nearly 20\% of the approximately 100 MSC-based clinical trials registered in the United States National Institutes of Health database are for bone and cartilage regeneration [20]. However, there is still a nascent understanding of long-term safety and efficacy of MSCbased therapies as most trials are in Phase I or Phase I/II. Interestingly, for the $\sim 33 \%$ of trials completed, there is evidence to suggest MSCs have therapeutic benefits that are not aligned with typical tissue engineering outcomes (e.g., tissue-specific differentiation and tissue production), such as enhancing vascularization in patients with osteonecrosis of the hip [21]. Additional therapeutic effects include attenuating inflammation and stimulating proliferation, suggesting these effects are due to MSC production of cytokines and growth factors that exhibit paracrine and/or autocrine effects [22].

Ultimately, cell phenotype and function are coordinated by a myriad of spatiotemporally regulated growth factors to realize bone regeneration. These factors include transforming growth factors (TGFs), bone morphogenetic proteins (BMPs), stromal cell-derived factor 1 (SDF1), and osteoprotegerin (OPG) (Figure 1). Based on these factors, a variety of drugs, including BMPs, other growth factors, hormones, and monoclonal antibodies, have been explored for bone regenerative effects [20,23]. Common strategies focus on BMP therapy, as canonical BMP signaling is integral to bone formation [13,24]. In fact, drug delivery approaches that increase the 
availability of factors such as BMP2 have been proven safe and efficacious for bone regeneration (e.g., INFUSE ${ }^{\mathrm{TM}}$ [6]); however, protein (e.g., antibodies, growth factors) half-lives are only on the order of an hour [25], necessitating local delivery of supra-physiological doses to achieve desired pharmacodynamics.

As an alternative to BMP, small molecule drugs such as statins that induce BMP signaling [26] and osteoregenerative agents that act on BMP-convergent pathways may also enhance bone remodeling $[27,28]$. These convergent pathways, including parathyroid hormone (PTH) and Wnt, stimulate osteogenesis and preserve osteoblasts when activated (Figure 2). Activated PTH receptor initiates Wnt signaling by complexing with low density lipoprotein receptor-related protein 5 and 6 (LRP5/6) [28], and Wnt signaling regulates targets common to BMP signaling [29]. Teriparatide (PTH 1-34), which is approved to treat osteoporosis, is used off-label in normal bone fractures, delayed bone fractures [30], and non-unions [31], and patients demonstrate accelerated healing. Lithium, a Wnt signaling agonist that negatively regulates glycogen synthase kinase 3 beta (GSK3 3 ) [32], and a monoclonal antibody that inhibits the Wntinhibitory protein sclerostin [33] accelerate fracture healing since Wnt signaling is critical for fracture repair [34]. Wnt, PTH, and BMP play key roles in specific stages of fracture repair [35,36], but they can also be inhibitory if activated without proper spatiotemporal control [37].

While many growth factor-based bone regenerative therapies have been explored, many require invasive procedures and/or require supra-physiological factor delivery to achieve efficacy, resulting in therapies that are cost prohibitive (\$5000 to $\$ 6000$ per package [38]) and include risks for harmful side effects [39]. As an alternative strategy to augment cell function and enhance bone remodeling, controlled drug delivery approaches amenable to systemic delivery avoid invasive procedures and minimize off-target cell behaviors. 


\section{Controlled drug delivery to bone}

To augment bone regeneration, there is a need to isolate delivery to the bone [4,40-43] This is due, in part, to mitigate off-target effects commonly associated with signaling pathway crosstalk [44] as a result of poorly controlled drug delivery. Drug depots and targeted systemically delivered carriers that present drugs to cells on demand may enhance the efficacy and reduce the potential toxicity of regenerative drugs.

Drug depots

Basic diffusion dependent drug depots consist of a drug loaded within a carrier: for example, BMP2 loaded into the collagen-based scaffold of INFUSE ${ }^{\mathrm{TM}}$ [6]. Diffusion dependent depots often demonstrate an initial uncontrolled burst release of drug followed by first order release dictated by the size of drug relative to the pore or mesh size of the carrier. Thus, cells are exposed to drug as soon as the carrier is implanted, which may be undesirable because MSC differentiation is sensitive to the timing of growth factor presentation [45].

Greater control over drug release can be achieved through depots that respond to environmental stimuli, including enzymatic activity and changes in $\mathrm{pH}$. A variety of matrix metalloproteinases (MMPs) are expressed during bone formation and remodeling [46,47]. Drugs modified with peptide sequences sensitive to MMPs can be linked within hydrogel depots and released upon MMP activity [48]. Alternatively, drugs can be encapsulated in hydrogels that degrade via MMP cleavage. Designed from $\alpha(1)$-chain type I collagen, the peptide sequence GPQGIWGQ is cleaved by multiple MMPs [49], and a derivative of this sequence was the crosslinker for poly(ethylene glycol) hydrogels containing BMP2 [50]. Upon implantation, degradation, and increase in hydrogel mesh size, the hydrogels released BMP2. This resulted in 
regeneration of critical-sized calvarial defects in four weeks, with the amount of bone regeneration directly correlated to crosslinker MMP degradation rate. Radiopacities of the defects were greater than $90 \%$ for the faster degrading hydrogels, greater than $75 \%$ for the slower degrading hydrogels, and greater than $40 \%$ for the non-degrading hydrogels. Similarly, the peptide sequence VPMSMRGG, which is cleaved by MMP1 and MMP2, was incorporated as the crosslinker for maleimide-functionalized hyaluronic hydrogels containing BMP2 [51]. When implanted in critical-sized calvarial defects, the fastest degrading hydrogels resulted in significantly greater bone regeneration in six weeks. The ratio of bone volume to total volume in the defect was approximately 0.25 for the fastest degrading hydrogels, whereas the ratio for the slowest degrading hydrogels was only 0.15 , which was not significantly different from the ratios for untreated defects or unloaded hydrogels.

Therapeutically relevant concentrations of drug can be released from $\mathrm{pH}$-responsive carriers. For example, osteomyelitis, a condition characterized by an acidic environment, was treated with antibiotic released from $\mathrm{pH}$-responsive poly(D,L-lactic-co-glycolic acid) (PLGA) microspheres impregnated within calcium phosphate scaffolds [52]. These microspheres provide greater control over release versus scaffolds simply impregnated with antibacterial proteins [53]. Additionally, dental biofilms, which also present an acidic environment, were treated with $\mathrm{pH}$ responsive diblock copolymer nanoparticles containing anti-biofilm agents [54,55]. At physiological pH (7.2), 50\% of loaded drug was released within 15 hours, while at acidic $\mathrm{pH}$ (4.5), $50 \%$ of loaded drug was released within 7 hours. This approach may be useful in combination with or used in lieu of antibiotics to prevent biofilm colonization during bone regeneration [56].

Systemically delivered, targeted carriers 
While drug depots provide site-specific drug delivery, similar to cell transplantation, they often require invasive procedures for placement. The primary exception is an injectable formulation that assembles in situ. Although critical sized defects already require surgery to heal, smaller defects or closed fractures may not, and a surgery conducted to place a depot is counterproductive to healing. Alternatively, systemic injection of drug or drug-loaded polymer functionalized with a bone-targeting moiety provides a noninvasive technique for site-specific therapy (Figure 3). It is not necessary to administer this therapy upon insult to bone and instead can be administered at any time, such as in the case of a fracture that is not diagnosed immediately after injury or in the case of regenerating bone in individuals with osteoporosis and other systemic bone diseases.

Reviewed in-depth by Kopeček [57] and Luhmann [58], traditional bone-targeting moieties that bind strongly (dissociation constant, $\mathrm{K}_{\mathrm{D}}$, in the micromolar range) to the mineral phase of bone include bisphosphonates, acidic oligopeptides, and tetracycline. More recently, derivatives of anthraquinone were found to bind hydroxyapatite mineral and may be used to deliver non-steroidal anti-inflammatory drugs to arthritic bone [59]. It is also possible to target the organic phase of bone by using collagen binding domain (CBD) peptides derived from Clostridium histolyticum $(\mathrm{ColH})$ collagenase, where CBD can be a synthetic extension of a peptide drug [60].

Despite gains in bone distribution relative to untargeted drugs, traditional targeted carriers exhibit poor bone accumulation in terms of percent injected dose measures, perhaps due to a lack of specific binding. Alternative high-affinity $\left(\mathrm{K}_{\mathrm{D}}\right.$ in the nanomolar to picomolar range) bone-targeting peptides and aptamers (Figure 3) may be found through libraries of peptide and nucleic acid sequences designed to specifically bind target proteins, molecules, or cells in bone 
(Table 1). Studies have used phage displays to identify peptides that bind to hydroxyapatite [61,62], collagen [63], tartrate-resistant acid phosphatase (TRAP) [64], bone marrow stromal cells [65], osteoblasts [66-68], and bone marrow endothelial cells [69]. While many of these studies were focused on cell interactions and not targeting drugs to bone, peptides may be incorporated into polymer carriers or synthesized as fusion peptides with therapeutic sequences. Another study used cell-based systematic evolution of ligands by exponential enrichment (cellSELEX) technology to design an osteoblast-specific aptamer-decorated liposome to deliver siRNA to bone and promote osteoblast function [70], and various aptamers have been designed to selectively bind to osteoblasts [71], bone marrow MSCs [72], osteoprogenitor cells [73], and C-telopeptide of human type I bone collagen (CTX) [74]. While many of these aptamers are used for characterizing cells, they can conceivably be applied to drug delivery approaches.

Complementing the strategy of primary targeting, a pro-drug approach can ensure drugs are released only upon successful delivery to bone. Linkers placed between a drug and a carrier can be developed to be cleaved only by enzymes or stimuli localized at the site of repair. Just as MMP cleavage is used to release drugs from hydrogel depots, so too are drugs released from carriers following MMP cleavage of labile linkers (Figure 3). Following fracture and during remodeling, osteoclasts produce enzymes, such as cathepsin $\mathrm{K}$, and create an acidic environment [4]. Thus, linkers sensitive to enzymes or low $\mathrm{pH}$ could be introduced to enable selective release at resorption surfaces. For example, the peptide sequences GGGMGPSGPWGGK [75], HPGGPQ [76,77], and GGP-Nle [78], which are substrates for cathepsin K, or polyketals [79,80], acetals [80], and hydrazones [81-83], which are acid-labile bonds, could be incorporated. By using linkers dependent on osteoclast bone catabolism, rate of release may be matched to the required regenerative response because osteoclasts appear early in the repair 
process, increase in number during soft and hard callus formation, and decrease during resolution [84-86].

\section{Future Perspectives}

Bone regeneration may benefit from a customizable, targeted approach to treatment. This customization may be at the level of intra-operative decisions, wherein a specific composition of drug and linker may be applied through a patient-specific drug delivery patch, strip, or sleeve [87]. However, it is important to maintain simplicity to facilitate clinical adoption of new technologies. Delivering stimuli-responsive depots or polymers enables customization without $a$ priori knowledge of a patient's condition or on-the-spot modifications since stimuli (e.g. enzymes or low $\mathrm{pH}$ ) are presented in situ over time. Each stage of bone regeneration is characterized by a distinct microenvironment and a distinct signaling molecule profile. Therefore, if the natural healing cascade is emulated via multi-drug release of osteoregeneratives by enzymatic or other chemical activities that dominate during times at which drugs are most beneficial, a new frontier for bolstering bone regeneration may soon be realized.

\section{Acknowledgements}

This work was supported by NSF CBET-1450987, NSF DGE-1419118, NSF DMR-1206219, and NIH AR064200. The authors thank Dominic Malcolm, Andrew Shubin, Kenneth Sims, and Yuchen Wang for helpful critiques of manuscript drafts. 
1. Novicoff WM, Manaswi A, Hogan MV, Brubaker SM, Mihalko WM, Saleh KJ: Critical analysis of the evidence for current technologies in bone-healing and repair. $J$ Bone Joint Surg Am 2008, 90 Suppl 1:85-91.

2. Santolini E, West R, Giannoudis PV: Risk factors for long bone fracture non-union: a stratification approach based on the level of the existing scientific evidence. Injury 2015, 46 Suppl 8:S8-S19.

3. Marsell R, Einhorn TA: The biology of fracture healing. Injury 2011, 42:551-555.

4. Schindeler A, McDonald MM, Bokko P, Little DG: Bone remodeling during fracture repair: The cellular picture. Semin Cell Dev Biol 2008, 19:459-466.

5. Claes L, Recknagel S, Ignatius A: Fracture healing under healthy and inflammatory conditions. Nat Rev Rheumatol 2012, 8:133-143.

6. Ratko TA, Belinson SE, Samson DJ, Bonnell C, Ziegler KM, Aronson N: In Bone Morphogenetic Protein: The State of the Evidence of On-Label and Off-Label Use; 2010.

7. Dominici M, Le Blanc K, Mueller I, Slaper-Cortenbach I, Marini F, Krause D, Deans R, Keating A, Prockop D, Horwitz E: Minimal criteria for defining multipotent mesenchymal stromal cells. The International Society for Cellular Therapy position statement. Cytotherapy 2006, 8:315-317.

8. Cuthbert RJ, Giannoudis PV, Wang XN, Nicholson L, Pawson D, Lubenko A, Tan HB, Dickinson A, McGonagle D, Jones E: Examining the feasibility of clinical grade CD271+ enrichment of mesenchymal stromal cells for bone regeneration. PLoS One 2015, 10:e0117855.

9. Briquet A, Halleux A, Lechanteur C, Beguin Y: Neuropeptides to replace serum in cryopreservation of mesenchymal stromal cells? Cytotherapy 2013, 15:1385-1394.

10. Lennon DP, Schluchter MD, Caplan AI: The effect of extended first passage culture on the proliferation and differentiation of human marrow-derived mesenchymal stem cells. Stem Cells Transl Med 2012, 1:279-288.

11. Pogozhykh D, Prokopyuk V, Pogozhykh O, Mueller T, Prokopyuk O: Influence of Factors of Cryopreservation and Hypothermic Storage on Survival and Functional Parameters of Multipotent Stromal Cells of Placental Origin. PLoS One 2015, 10:e0139834.

12. Yong KW, Wan Safwani WK, Xu F, Wan Abas WA, Choi JR, Pingguan-Murphy B: Cryopreservation of Human Mesenchymal Stem Cells for Clinical Applications: Current Methods and Challenges. Biopreserv Biobank 2015, 13:231-239.

(•) 13. Rogers MB, Shah TA, Shaikh NN: Turning Bone Morphogenetic Protein 2 (BMP2) on and off in Mesenchymal Cells. J Cell Biochem 2015, 116:2127-2138.

This review discusses regulation of BMP2 signaling and notes additional molecules and conditions that induce BMP2 signaling.

14. Rennerfeldt DA, Van Vliet KJ: When colonies are not clones: Evidence and implications of intracolony heterogeneity in mesenchymal stem cells. Stem Cells 2016.

15. Mehta M, Schmidt-Bleek K, Duda GN, Mooney DJ: Biomaterial delivery of morphogens to mimic the natural healing cascade in bone. Adv Drug Deliv Rev 2012, 64:12571276.

16. Hoffman MD, Benoit DS: Agonism of Wnt-beta-catenin signalling promotes mesenchymal stem cell (MSC) expansion. J Tissue Eng Regen Med 2015, 9:E13-26.

17. de Peppo GM, Marolt D: Make no bones about it: cells could soon be reprogrammed to grow replacement bones? Expert Opinion on Biological Therapy 2014, 14:1-5. 
18. Tran C, Damaser MS: Stem cells as drug delivery methods: Application of stem cell secretome for regeneration. Advanced Drug Delivery Reviews 2015, 82-83:1-11.

(••) 19. Srijaya TC, Ramasamy TS, Kasim NH: Advancing stem cell therapy from bench to bedside: lessons from drug therapies. $J$ Transl Med 2014, 12:243.

The authors highlight challenges of stem cell therapies and hypothesize that efficacy of cell-based therapies can be augmented by applying techniques used to develop synthetic drug delivery systems.

20. Squillaro T, Peluso G, Galderisi U: Clinical Trials with Mesenchymal Stem Cells: An Update. Cell Transplant 2015.

21. Kawate K, Yajima H, Ohgushi H, Kotobuki N, Sugimoto K, Ohmura T, Kobata Y, Shigematsu K, Kawamura K, Tamai K, et al.: Tissue-engineered approach for the treatment of steroid-induced osteonecrosis of the femoral head: transplantation of autologous mesenchymal stem cells cultured with beta-tricalcium phosphate ceramics and free vascularized fibula. Artif Organs 2006, 30:960-962.

22. Caplan AI, Dennis JE: Mesenchymal stem cells as trophic mediators. J Cell Biochem 2006, 98:1076-1084.

(•) 23. Gothard D, Smith EL, Kanczler JM, Rashidi H, Qutachi O, Henstock J, Rotherham M, El Haj A, Shakesheff KM, Oreffo RO: Tissue engineered bone using select growth factors: A comprehensive review of animal studies and clinical translation studies in man. Eur Cell Mater 2014, 28:166-207; discussion 207-168.

This comprehensive review compiles different growth factors, drug carriers, animal models, and human trials from bone tissue engineering in the time frame of 1965 to 2013.

(•) 24. Hayrapetyan A, Jansen JA, van den Beucken JJJP: Signaling Pathways Involved in Osteogenesis and Their Application for Bone Regenerative Medicine. Tissue Engineering Part B-Reviews 2015, 21:75-87.

This review highlights the signaling pathways essential to osteogenic differentiation of MSCs and identifies the effects of growth factors on these pathways.

25. Mitchell AC, Briquez PS, Hubbell JA, Cochran JR: Engineering growth factors for regenerative medicine applications. Acta Biomater 2016, 30:1-12.

26. Ruan F, Zheng Q, Wang J: Mechanisms of bone anabolism regulated by statins. Biosci Rep 2012, 32:511-519.

(•) 27. Martin TJ: Bone biology and anabolic therapies for bone: current status and future prospects. J Bone Metab 2014, 21:8-20.

This review describes cells in bone, the remodeling process, and mechanisms of action for proven and potential osteoregenerative treatments for osteoporosis.

28. Baron R, Kneissel M: WNT signaling in bone homeostasis and disease: from human mutations to treatments. Nat Med 2013, 19:179-192.

29. Itasaki N, Hoppler S: Crosstalk Between Wnt and Bone Morphogenic Protein Signaling: A Turbulent Relationship. Developmental Dynamics 2010, 239:16-33.

30. Peichl P, Holzer LA, Maier R, Holzer G: Parathyroid Hormone 1-84 Accelerates Fracture-Healing in Pubic Bones of Elderly Osteoporotic Women. Journal of Bone and Joint Surgery-American Volume 2011, 93a:1583-1587.

31. Coppola C, Del Buono A, Maffulli N: Teriparatide in Fracture Non-Unions. Transl Med UniSa 2015, 12:47-53.

(•) 32. Wang X, Zhu S, Jiang X, Li Y, Song D, Hu J: Systemic administration of lithium improves distracted bone regeneration in rats. Calcif Tissue Int 2015, 96:534-540. 
This paper is the first to use lithium as a Wnt agonist in a model of distraction osteogenesis.

33. Feng G, Chang-Qing Z, Yi-Min C, Xiao-Lin L: Systemic administration of sclerostin monoclonal antibody accelerates fracture healing in the femoral osteotomy model of young rats. Int Immunopharmacol 2015, 24:7-13.

34. Xu H, Duan J, Ning D, Li J, Liu R, Yang R, Jiang JX, Shang P: Role of Wnt signaling in fracture healing. BMB Rep 2014, 47:666-672.

35. Chen Y, Whetstone HC, Lin AC, Nadesan P, Wei Q, Poon R, Alman BA: Beta-catenin signaling plays a disparate role in different phases of fracture repair: implications for therapy to improve bone healing. PLoS Med 2007, 4:e249.

36. Rozen N, Lewinson D, Bick T, Jacob ZC, Stein H, Soudry M: Fracture repair: modulation of fracture-callus and mechanical properties by sequential application of IL-6 following PTH 1-34 or PTH 28-48. Bone 2007, 41:437-445.

37. McGee-Lawrence ME, Carpio LR, Bradley EW, Dudakovic A, Lian JB, van Wijnen AJ, Kakar S, Hsu W, Westendorf JJ: Runx2 is required for early stages of endochondral bone formation but delays final stages of bone repair in Axin2-deficient mice. Bone 2014, 66:277-286.

38. Epstein NE: Pros, cons, and costs of INFUSE in spinal surgery. Surg Neurol Int 2011, 2:10.

39. Lienemann PS, Lutolf MP, Ehrbar M: Biomimetic hydrogels for controlled biomolecule delivery to augment bone regeneration. Advanced Drug Delivery Reviews 2012, 64:1078-1089.

(•) 40. Martino MM, Briquez PS, Maruyama K, Hubbell JA: Extracellular matrix-inspired growth factor delivery systems for bone regeneration. Adv Drug Deliv Rev 2015. This review highlights the design of extracellular matrix-mimetic drug delivery systems that exploit interactions between growth factors and the local environment.

(••) 41. Samorezov JE, Alsberg E: Spatial regulation of controlled bioactive factor delivery for bone tissue engineering. Advanced Drug Delivery Reviews 2015, 84:45-67. This review discusses state-of-the art fabrication methods for bone tissue engineering scaffolds with control over the spatial patterning and release of drugs that influence bone development and healing.

(••) 42. Nyberg E, Holmes C, Witham T, Grayson WL: Growth factor-eluting technologies for bone tissue engineering. Drug Deliv Transl Res 2015.

This review introduces various techniques to design bone tissue engineering scaffolds with controlled drug release kinetics.

43. King WJ, Krebsbach PH: Growth factor delivery: how surface interactions modulate release in vitro and in vivo. Adv Drug Deliv Rev 2012, 64:1239-1256.

44. Biver E, Thouverey C, Magne D, Caverzasio J: Crosstalk between tyrosine kinase receptors, GSK3 and BMP2 signaling during osteoblastic differentiation of human mesenchymal stem cells. Molecular and Cellular Endocrinology 2014, 382:120-130.

(•) 45. Correa D, Somoza RA, Lin P, Greenberg S, Rom E, Duesler L, Welter JF, Yayon A, Caplan AI: Sequential exposure to fibroblast growth factors (FGF) 2, 9 and 18 enhances hMSC chondrogenic differentiation. Osteoarthritis Cartilage 2015, 23:443453.

The authors identify that the timing of FGF presentation to MSCs influences chondrogenic differentiation. 
46. Ortega N, Behonick DJ, Werb Z: Matrix remodeling during endochondral ossification. Trends Cell Biol 2004, 14:86-93.

47. Haeusler G, Walter I, Helmreich M, Egerbacher M: Localization of matrix metalloproteinases, (MMPs) their tissue inhibitors, and vascular endothelial growth factor (VEGF) in growth plates of children and adolescents indicates a role for MMPs in human postnatal growth and skeletal maturation. Calcif Tissue Int 2005, 76:326-335.

48. Van Hove AH, Benoit DS: Depot-Based Delivery Systems for Pro-Angiogenic Peptides: A Review. Front Bioeng Biotechnol 2015, 3:102.

49. Lutolf MP, Hubbell JA: Synthesis and physicochemical characterization of end-linked poly(ethylene glycol)-co-peptide hydrogels formed by Michael-type addition. Biomacromolecules 2003, 4:713-722.

50. Lutolf MP, Lauer-Fields JL, Schmoekel HG, Metters AT, Weber FE, Fields GB, Hubbell JA: Synthetic matrix metalloproteinase-sensitive hydrogels for the conduction of tissue regeneration: engineering cell-invasion characteristics. Proc Natl Acad Sci U S A 2003, 100:5413-5418.

(•) 51. Holloway JL, Ma H, Rai R, Burdick JA: Modulating hydrogel crosslink density and degradation to control bone morphogenetic protein delivery and in vivo bone formation. J Control Release 2014, 191:63-70.

This paper demonstrates how careful design of MMP-sensitive hydrogel networks can optimize BMP2 release and heal critical-sized calvarial defects.

52. Chung MF, Chia WT, Liu HY, Hsiao CW, Hsiao HC, Yang CM, Sung HW: InflammationInduced Drug Release by using a pH-Responsive Gas-Generating HollowMicrosphere System for the Treatment of Osteomyelitis. Advanced Healthcare Materials 2014, 3:1854-1861.

53. Xue B, Zhang C, Wang YH, Wang JC, Zhang J, Lu M, Li GD, Cao ZH, Huang QS: A Novel Controlled-Release System for Antibacterial Enzyme Lysostaphin Delivery Using Hydroxyapatite/Chitosan Composite Bone Cement. Plos One 2014, 9.

54. Horev B, Klein MI, Hwang G, Li Y, Kim D, Koo H, Benoit DS: pH-activated nanoparticles for controlled topical delivery of farnesol to disrupt oral biofilm virulence. ACS Nano 2015, 9:2390-2404.

55. Zhou J, Horev B, Geelsu H, Klein MI, Koo H, Benoit DS: Characterization and optimization of pH-responsive polymer nanoparticles for drug delivery to oral biofilms. J Mater Chem B 2016.

56. Hickok NJ, Shapiro IM: Immobilized antibiotics to prevent orthopaedic implant infections. Adv Drug Deliv Rev 2012, 64:1165-1176.

57. Low SA, Kopecek J: Targeting polymer therapeutics to bone. Adv Drug Deliv Rev 2012, 64:1189-1204.

58. Luhmann T, Germershaus O, Groll J, Meinel L: Bone targeting for the treatment of osteoporosis. J Control Release 2012, 161:198-213.

59. Cai J, Duan Y, Yu J, Chen J, Chao M, Ji M: Bone-targeting glycol and NSAIDS ester prodrugs of rhein: synthesis, hydroxyapatite affinity, stability, anti-inflammatory, ulcerogenicity index and pharmacokinetics studies. Eur J Med Chem 2012, 55:409419. 
(••) 60. Ponnapakkam T, Katikaneni R, Sakon J, Stratford R, Gensure RC: Treating osteoporosis by targeting parathyroid hormone to bone. Drug Discov Today 2014, 19:204-208.

This paper demonstrates how targeting PTH(1-34) to collagen builds bone while avoiding hypercalcemia, a side effect common to untargeted PTH(1-34) treatment.

61. Ramaswamy J, Nam HK, Ramaraju H, Hatch NE, Kohn DH: Inhibition of osteoblast mineralization by phosphorylated phage-derived apatite-specific peptide. Biomaterials 2015, 73:120-130.

62. Lee JS, Lee JS, Murphy WL: Modular peptides promote human mesenchymal stem cell differentiation on biomaterial surfaces. Acta Biomater 2010, 6:21-28.

63. Hamilton PT, Jansen MS, Ganesan S, Benson RE, Hyde-Deruyscher R, Beyer WF, Gile JC, Nair SA, Hodges JA, Gron $\mathrm{H}$ : Improved bone morphogenetic protein-2 retention in an injectable collagen matrix using bifunctional peptides. PLoS One 2013, 8:e70715.

64. Sheu TJ, Schwarz EM, O'Keefe RJ, Rosier RN, Puzas JE: Use of a phage display technique to identify potential osteoblast binding sites within osteoclast lacunae. $J$ Bone Miner Res 2002, 17:915-922.

65. Ramaraju H, Miller SJ, Kohn DH: Dual-functioning phage-derived peptides encourage human bone marrow cell-specific attachment to mineralized biomaterials. Connect Tissue Res 2014, 55 Suppl 1:160-163.

66. Wu M, Zhou Y, Du M, Qian H, Li Q: [Phage display peptide library for screening the peptides that specifically bind to osteoblasts cells]. Zhonghua Kou Qiang Yi Xue Za Zhi 2015, 50:438-441.

67. t Hoen PA, Jirka SM, Ten Broeke BR, Schultes EA, Aguilera B, Pang KH, Heemskerk H, Aartsma-Rus A, van Ommen GJ, den Dunnen JT: Phage display screening without repetitious selection rounds. Anal Biochem 2012, 421:622-631.

68. Gil M, Kawai T, Ishikawa-Nagai S, Da Silva J, Nagai M: Identification of putative bone anabolic peptides targeting adherent plasma membrane. Biochem Biophys Res Commun 2015, 459:71-74.

69. Clement G, Bisoffi M, Finger AN, Wetterwald A, Thalmann GN, Cecchini MG:

Peptabodies as tools to test ligands isolated from phage-displayed peptide libraries. J Immunol Methods 2003, 276:135-141.

(••) 70. Liang C, Guo B, Wu H, Shao N, Li D, Liu J, Dang L, Wang C, Li H, Li S, et al.: Aptamer-functionalized lipid nanoparticles targeting osteoblasts as a novel RNA interference-based bone anabolic strategy. Nat Med 2015, 21:288-294.

The authors combine aptamers and Plekho1 siRNA in a lipid nanoparticle to selectively modulate gene expression in osteoblasts, subsequently increasing bone formation in a rodent model of osteoporosis.

71. Guo K, Wendel HP, Scheideler L, Ziemer G, Scheule AM: Aptamer-based capture molecules as a novel coating strategy to promote cell adhesion. Journal of Cellular and Molecular Medicine 2005, 9:731-736.

72. Schafer R, Wiskirchen J, Guo K, Neumann B, Kehlbach R, Pintaske J, Voth V, Walker T, Scheule AM, Greiner TO, et al.: Aptamer-based isolation and subsequent imaging of mesenchymal stem cells in ischemic myocard by magnetic resonance imaging. Rofo 2007, 179:1009-1015. 
73. Ardjomandi N, Niederlaender J, Aicher WK, Reinert S, Schweizer E, Wendel HP, Alexander D: Identification of an aptamer binding to human osteogenic-induced progenitor cells. Nucleic Acid Ther 2013, 23:44-61.

74. Bruno JG, Carrillo MP, Phillips T, Hanson D, Bohmann JA: DNA Aptamer Beacon Assay for C-Telopeptide and Handheld Fluorometer to Monitor Bone Resorption. Journal of Fluorescence 2011, 21:2021-2033.

75. Hsu CW, Olabisi RM, Olmsted-Davis EA, Davis AR, West JL: Cathepsin K-sensitive poly(ethylene glycol) hydrogels for degradation in response to bone resorption. $J$ Biomed Mater Res A 2011, 98:53-62.

76. Wang X, Yang Y, Jia H, Jia W, Miller S, Bowman B, Feng J, Zhan F: Peptide Decoration of Nanovehicles to Achieve Active Targeting and Pathology-Responsive Cellular Uptake for Bone Metastasis Chemotherapy. Biomater Sci 2014, 2:961-971.

77. Jaffer FA, Kim DE, Quinti L, Tung CH, Aikawa E, Pande AN, Kohler RH, Shi GP, Libby P, Weissleder R: Optical visualization of cathepsin $\mathrm{K}$ activity in atherosclerosis with a novel, protease-activatable fluorescence sensor. Circulation 2007, 115:2292-2298.

78. Pan H, Sima M, Miller SC, Kopeckova P, Yang J, Kopecek J: Efficiency of high molecular weight backbone degradable HPMA copolymer-prostaglandin E1 conjugate in promotion of bone formation in ovariectomized rats. Biomaterials 2013, 34:65286538.

79. Sohn YD, Somasuntharam I, Che PL, Jayswal R, Murthy N, Davis ME, Yoon YS: Induction of pluripotency in bone marrow mononuclear cells via polyketal nanoparticlemediated delivery of mature microRNAs. Biomaterials 2013, 34:4235-4241.

80. Falco EE, Patel M, Fisher JP: Recent developments in cyclic acetal biomaterials for tissue engineering applications. Pharm Res 2008, 25:2348-2356.

81. Hochdorffer K, Abu Ajaj K, Schafer-Obodozie C, Kratz F: Development of novel bisphosphonate prodrugs of doxorubicin for targeting bone metastases that are cleaved pH dependently or by cathepsin B: synthesis, cleavage properties, and binding properties to hydroxyapatite as well as bone matrix. $\mathrm{J} \mathrm{Med} \mathrm{Chem} \mathrm{2012,}$ 55:7502-7515.

(•) 82. Low SA, Yang J, Kopecek J: Bone-targeted acid-sensitive doxorubicin conjugate micelles as potential osteosarcoma therapeutics. Bioconjug Chem 2014, 25:2012-2020. The authors design a bone-targeted micelle delivery system with $\mathrm{pH}$-responsive drug release to deliver doxorubicin to osteosarcoma cells.

83. Liu XM, Quan LD, Tian J, Laquer FC, Ciborowski P, Wang D: Syntheses of click PEGdexamethasone conjugates for the treatment of rheumatoid arthritis. Biomacromolecules 2010, 11:2621-2628.

84. Aro HT, Wippermann BW, Hodgson SF, Chao EY: Internal remodeling of periosteal new bone during fracture healing. J Orthop Res 1990, 8:238-246.

85. Schell H, Lienau J, Epari DR, Seebeck P, Exner C, Muchow S, Bragulla H, Haas NP, Duda GN: Osteoclastic activity begins early and increases over the course of bone healing. Bone 2006, 38:547-554.

86. Kawakatsu M, Kanno S, Gui T, Gai Z, Itoh S, Tanishima H, Oikawa K, Muragaki Y: Loss of Smad3 gives rise to poor soft callus formation and accelerates early fracture healing. Exp Mol Pathol 2011, 90:107-115. 
87. Trajkovski B, Petersen A, Strube P, Mehta M, Duda GN: Intra-operatively customized implant coating strategies for local and controlled drug delivery to bone. Adv Drug Deliv Rev 2012, 64:1142-1151. 


\section{FIGURES}

\section{Figure 1}

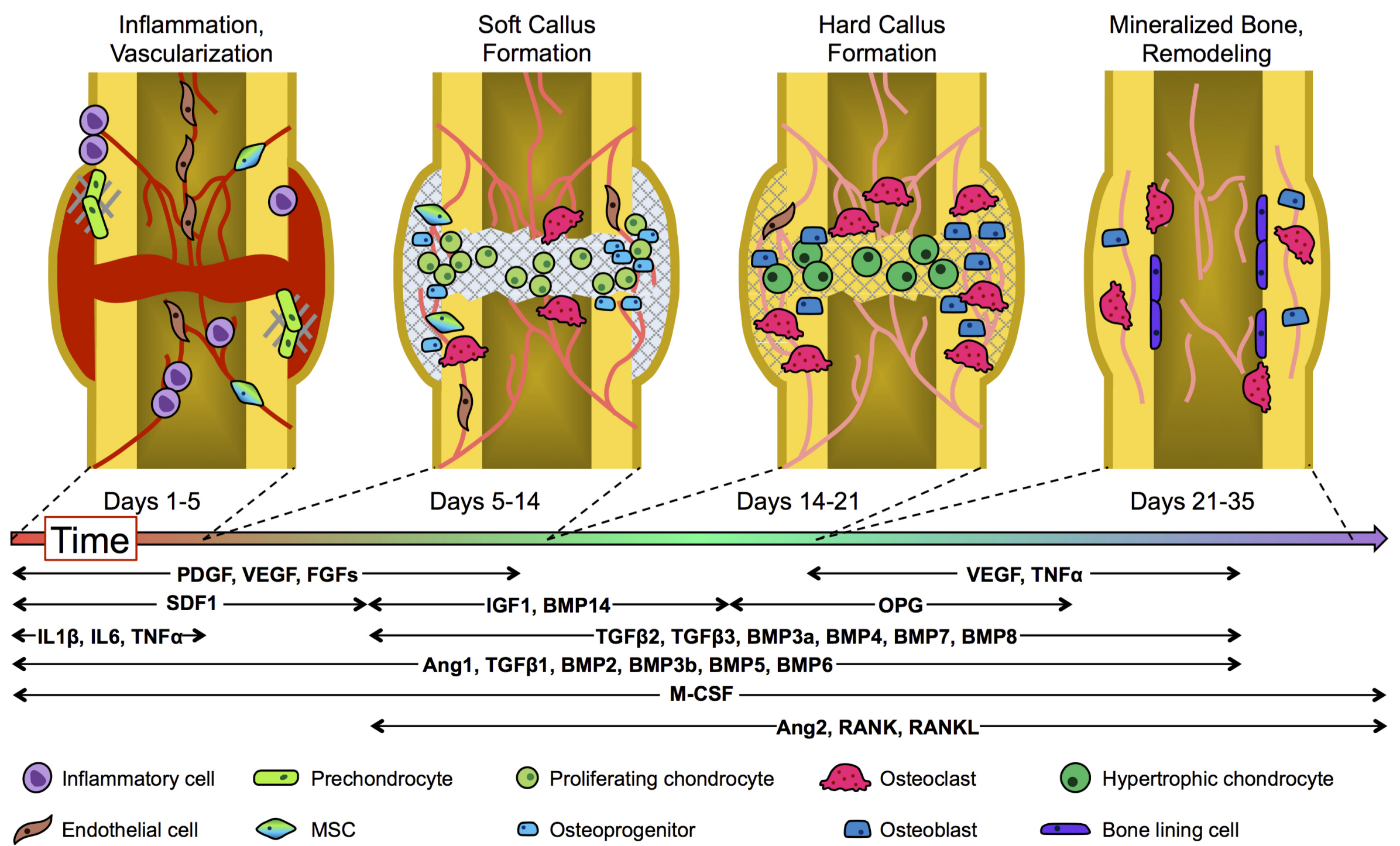

Figure 1: A spatiotemporal cascade of multiple endogenous factors controls normal bone regeneration during fracture repair in four stages. PDGF = platelet derived growth factor; VEGF = vascular endothelial growth factor; FGF = fibroblast growth factor; TNF = tumor necrosis factor; SDF = stromal cell-derived factor; IGF = insulin-like growth factor; BMP = bone morphogenetic protein; OPG = osteoprotegerin; IL = interleukin; TGF = transforming growth factor; Ang = angiopoietin; $\mathrm{M}-\mathrm{CSF}=$ macrophage colony stimulating factor; RANK = receptor activator of nuclear factor $K B ;$ RANKL = RANK-ligand. 
Figure 2

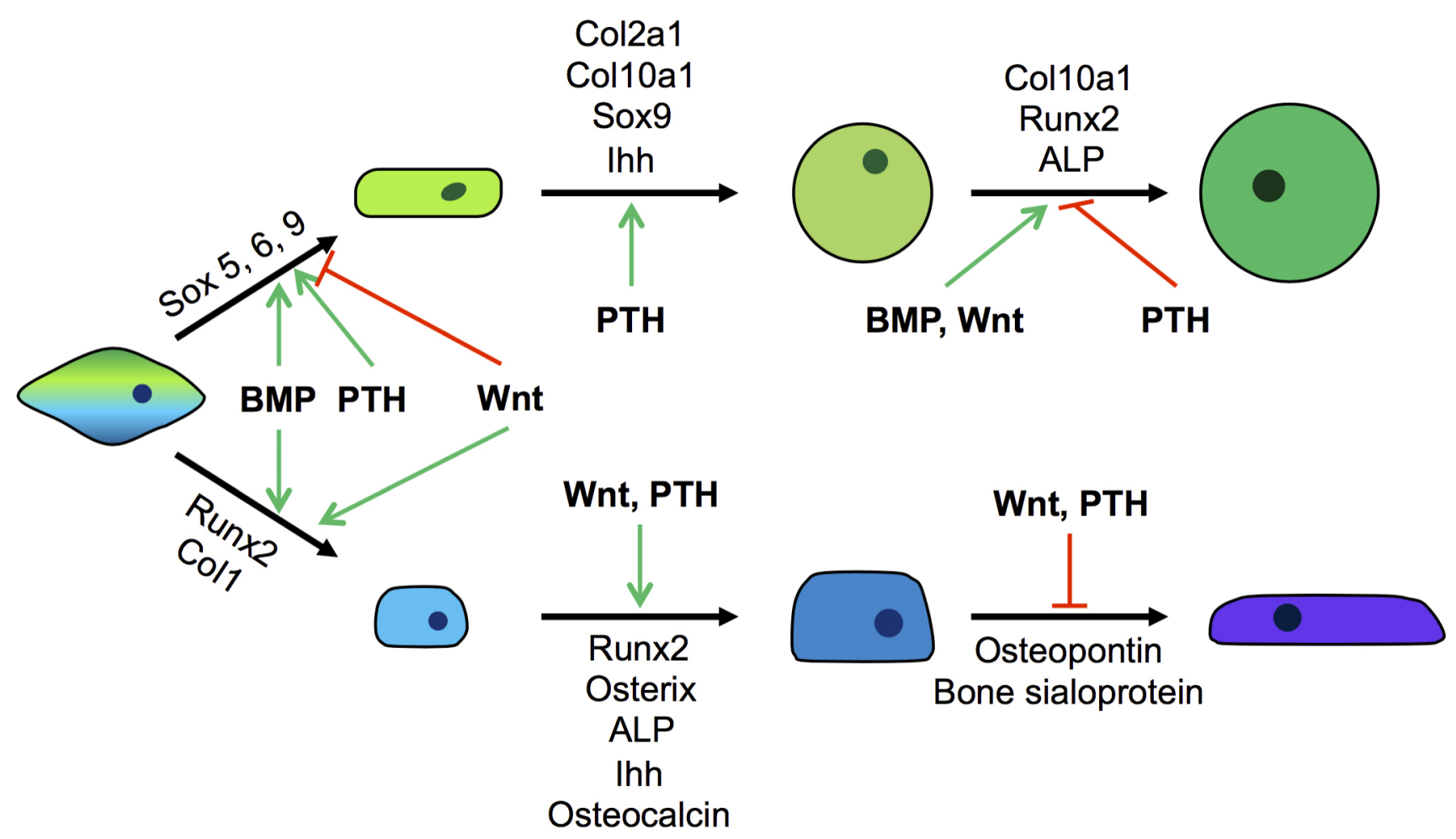

Figure 2: Mesenchymal stem cell chondrogenesis and osteogenesis are regulated by specific gene expression that is influenced by BMP, Wnt, and PTH signaling. Symbols indicating the various cell types are consistent with Figure 1. 


\section{Figure 3}

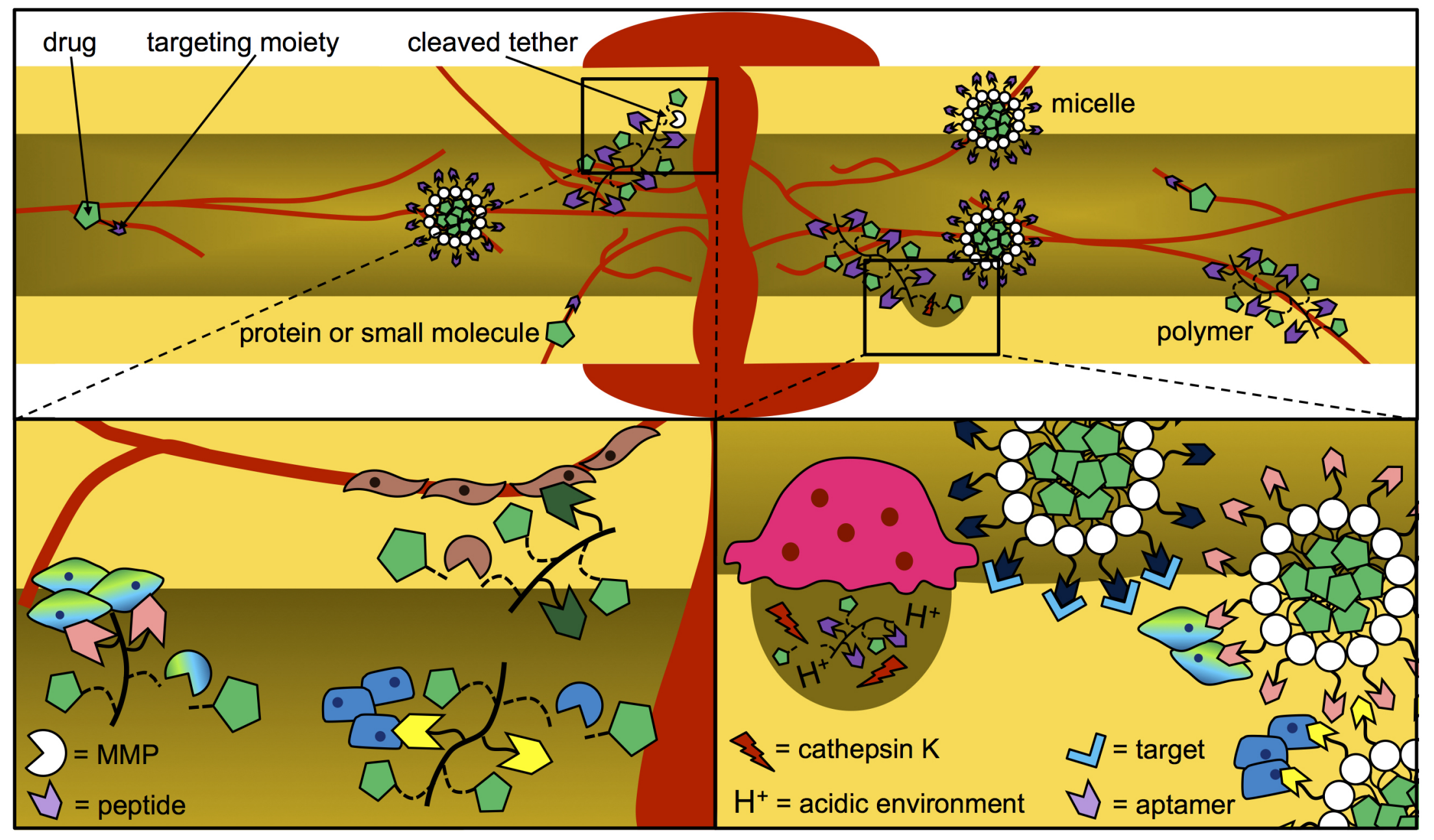

Figure 3: Targeted, systemic drug delivery uses targeting moieties (e.g. peptides and aptamers) to deliver drugs to bone. Carriers travel through the bloodstream and exit upon targeting. Drugs are cleaved via MMP and enzymatic activity or due to a change in $\mathrm{pH}$. Symbols indicating the various cell types are consistent with Figure 1. 
Table 1: Specific peptide and aptamer targets and synthetic sequences. Peptides are written N-to-C terminus using standard amino acid abbreviations ( $\mathrm{YE}=\mathrm{\gamma}$-carboxylated glutamic acid), and aptamers are written 5'-to-3' using standard oligonucleotide abbreviations.

\begin{tabular}{|c|c|c|c|c|}
\hline Target & Peptide & & Aptamer & \\
\hline Collagen & $\begin{array}{l}\text { PNNSKETASGPIVPGIPVSGTIE } \\
\text { NTSDQDYFYFDVITPGEVKIDI } \\
\text { NKLGYGGATWVYDENNNA } \\
\text { VSYATDDGQNLSGKFKADKP } \\
\text { GRYYIHLYMFNGSYMPYRINI } \\
\text { EGSVGR } \\
\text { SWWGFWNGSAAPVWSR }\end{array}$ & [60] & GGTGGTGTTGGCTCC & [74] \\
\hline Hydroxyapatite & $\begin{array}{l}\text { VTKHLNQISQSY } \\
\text { YEPRRYEVCYEL }\end{array}$ & $\begin{array}{l}{[61]} \\
{[62]}\end{array}$ & & \\
\hline TRAP & TPLSYLKGLVTV & [64] & & \\
\hline Bone marrow MSCs & DPIYALSWSGMA & [65] & $\begin{array}{l}\text { GAATTCAGTCGGACAGCG- } \\
\text { N40-GATGGACGATATCGT } \\
\text { CTCCC }\end{array}$ & [72] \\
\hline Osteoprogenitors & & & $\begin{array}{l}\text { GGGAGACAAGAATAAACGCTC } \\
\text { AACAAATGGGTGGGTGTGG } \\
\text { TGGGTGTGAAGGTGCGAGT } \\
\text { TGATTCGACAGGAGGCTCA } \\
\text { CAACAGGC }\end{array}$ & [73] \\
\hline Osteoblasts & $\begin{array}{l}\text { MGWSWWPETWPM } \\
\text { YRAPWPP } \\
\text { GKIHRHRGQAVE } \\
\text { ESHCLLGISCVL }\end{array}$ & $\begin{array}{l}{[66]} \\
{[67]} \\
{[68]} \\
{[68]}\end{array}$ & $\begin{array}{l}\text { AGTCTGTTGGACCGAATCCCG } \\
\text { TGGACGCACCCTTTGGACG } \\
\text { GAATTCAGTCGGACAGCGCAC } \\
\text { ACGGAACCTCGGAACACAG } \\
\text { CTAGCGGGGCTCACTGGAT } \\
\text { GGACGATATCGTCTCCC }\end{array}$ & $\begin{array}{l}{[70]} \\
{[71]}\end{array}$ \\
\hline Bone marrow endothelial cells & $\begin{array}{l}\text { MGGTVESCLAKSHTENSFTNV } \\
\text { WKDDKTLDRYANYEGCLWN } \\
\text { ATGVVVTGDETQCYGTWV } \\
\text { PIGLAIPEN }\end{array}$ & [69] & & \\
\hline
\end{tabular}




\section{Graphical Abstract}
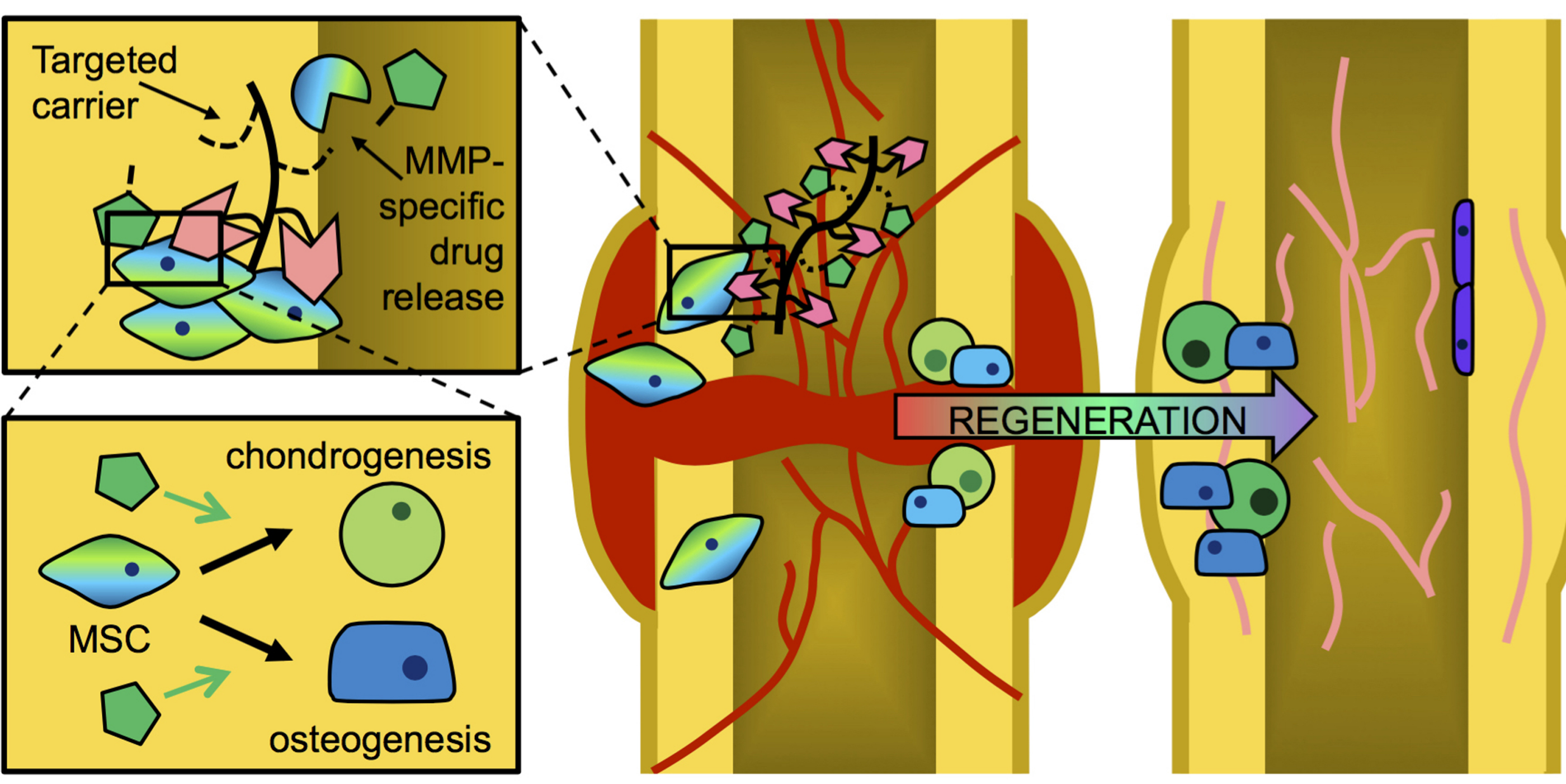